\title{
RELATIONSHIP OF BODE INDEX TO FUNCTIONAL TESTS IN CHRONIC OBSTRUCTIVE PULMONARY DISEASE
}

\author{
Eloisa Maria Gatti Regueiro, ${ }^{\mathrm{I}}$ Valéria Amorim Pires Di Lorenzo, ${ }^{\mathrm{I}}$ Renata

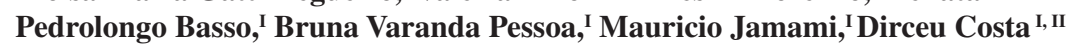

doi: 10.1590/S1807-59322009001000008

Regueiro EMG, Pires Di Lorenzo VA, Basso RP, Pessoa BV, Jamami M, Costa D. Relationship of bode index to functional tests in chronic obstructive pulmonary disease. Clinics. 2009;64(10):983-8.

OBJECTIVE: To determine if there is a correlation between the BODE Index and variables assessed during the Activities of Daily Living assessment, performance on lower limber tests, and peripheral muscle impairment of the upper limb in patients with chronic obstructive pulmonary disease.

MATERIALS AND METHODS: Ten men (aged 58 to 80 years old) with moderate to very severe obstruction were evaluated and classified by the BODE Index. They were evaluated by pulmonary ventilation $\left(\dot{V}_{\mathrm{E}}\right)$, oxygen consumption $\left(\dot{V} \mathrm{O}_{2}\right)$, and carbonic gas production $\left(\dot{V} \mathrm{CO}_{2}\right)$ on the ADL assessment; Distance Walking (DW) in the Six Minute Walking Test (6MWT) and the Six Minute Walking Test on Treadmill (6MWTT); number of repetitions in the Sit-to-Stand Test; and the Hand Grip Strength Test. Correlations were evaluated between the classification and the tests performed (Pearson and Spearman test, $\mathrm{p}<0.05$ ).

RESULTS: The mean of the total score for the BODE Index was $2.80( \pm 1.03)$, with three patients scoring in the first quartile (Q1) and seven scoring in the second quartile (Q2). This Index showed a negative correlation with the 6MWTT (r=-0.86), the Sit-to-Stand Test $(\mathrm{r}=-0.66)$, and the Hand Grip Strength Test $(\mathrm{r}=-0.83)$.

CONCLUSIONS: Our results show that there is no correlation between the BODE Index and the ventilatory and metabolic responses in the Activities of Daily Living assessment. On the other hand, a correlation was observed between the BODE Index and the variables assessed in the 6MWTT, Sit-to-Stand Test, and Hand Grip Strength Test in moderate to very severe Chronic Obstructive Pulmonary Disease patients. This suggests that these tests can be employed as predictors of physical exercise capacity, perhaps as complementary tests to the BODE Index.

KEYWORDS: Respiratory Physiotherapy; Activities of Daily Living; Six Minute Walk Test; Sit-to-Stand Test; Hand Grip Strength.

\section{INTRODUCTION}

Chronic Obstructive Pulmonary Disease (COPD) is characterized by ventilatory, metabolic, and peripheral muscle limitation, dyspnea ${ }^{1,2}$ and reduced exercise capacity. These condition decrease functional capacity, ${ }^{3}$ compromising the performance of Activities of Daily Living (ADL) due to a reduction in ventilatory and metabolic reserves. ${ }^{4}$ These limitations may be related to significant weight

${ }^{\text {I }}$ Federal University of São Carlos, UFSCar - São Carlos/ SP, Brazil.

"ININOVE - São Paulo/ SP, Brazil.

Email: eloregueiro@yahoo.com.br

Tel: 55163351.8343

Received for publication on May 07, 2009

Accepted for publication on July 20, 2009 loss,${ }^{5}$ respiratory muscle weakness, ${ }^{6}$ reduced strength and endurance of the upper (UL) and lower limbs (LL), ${ }^{7}$ higher mortality, and a worsened overall quality of life. Thus, COPD is considered as a systemic disease, affecting not only the lungs, but also a number of other organs, including the peripheral musculature.

The ability to exert physical effort independently influences the survival of these patients, and, due to the seriousness of these changes, the mortality risk for patients with COPD can be assessed by the BODE Index (B - Body mass index; $\mathrm{O}$ - airflow Obstruction; D - Dyspnea; and $\mathrm{E}$ Exercise capacity), which is considered the best predictor of survival in these patients. ${ }^{8}$ For the BODE Index, exercise capacity is verified by the distance walked in the Six Minute 
Walking Test in a hallway (6MWT). Due to the impairments associated with COPD, however, exercise capacity must also be verified by other tests, such as the performance of ADL that require elevation of the UL and LL, the Six Minute Walking Test on a Treadmill (6MWTT),${ }^{9}$ the Sit-to-Stand Test (STST), ${ }^{10}$ and the Hand Grip Strength Test (HGT), ${ }^{11}$ in order to determine the survival and general state of health of these patients.

ADL are defined as tasks that individuals perform on a daily basis, such as dressing, eating, bathing, combing hair, sitting down, and moving from one place to another. ${ }^{12}$ Both the UL and the LL are involved in the most common ADL. The muscles that participate in the positioning of the UL, such as the trapezius, pectoralis minor, scalene, sternocleidomastoid, and intercostals, also perform ventilatory and postural functions. ${ }^{13}$ Therefore, the performance of ADL tests as part of the routine evaluation of patients with respiratory functions is indispensable.

The LL tests selected for our study are considered to be good functional evaluation predictors ${ }^{14,10}$ because they evaluate, even if indirectly, the musculature of the LL, which is debilitated in patients with COPD. Peripheral muscle strength of the hand and UL have been assessed by hand grip strength, which constitutes a relevant indicator in the analysis of the general state of strength in an individual ${ }^{11}$ and is essential for the performance of ADL.

No reports have correlated ventilatory and metabolic variables and the muscle strength of the UL to the BODE Index during the performance of ADL and LL and UL tests. Furthermore, no studies have addressed whether or not there is a relationship between the performance of these tests and the BODE Index.

The present study aimed to determine whether there is a correlation between the BODE Index and the variables evaluated during ADL assessment, in addition to LL and UL tests such as 6MWTT, STST, and HGT, in patients with COPD. We hypothesized that there would be a correlation between the BODE Index and the ventilatory and metabolic responses during the performance of ADL and LL tests, the variables assessed in LL tests, and muscle strength of the UL.

\section{MATERIALS AND METHODS}

For the present study, a cross-sectional design and a nonprobabilistic method were used. The power was calculated using the standard deviation and the mean difference in the principal variables of the BODE Index described in a previous pilot study.

This study was conducted in the Special Respiratory Physiotherapy Unit of the Institution. Initially, 12 men with moderate to very severe obstruction ${ }^{14}$, aged from 58 to 80 years old, were evaluated.

Ten patients completed the evaluations (five with moderate COPD, three with severe COPD, and two with very severe COPD). ${ }^{14}$ Among these patients, ten used a bronchodilator (BD) exclusively and seven used a BD and a prescription corticosteroid.

In accordance with the Brazilian National Health Council, ethics approval was obtained from the Ethics Committee of the Institution ( $\mathrm{n}^{\circ}$ 46/2007) and all patients provided written informed consent.

\section{Inclusion and Exclusion Criteria}

We included males with a clinical diagnosis of COPD confirmed by post-BD spirometry administered by a pneumologist, in accordance with the GOLD criteria, who were classified as having moderate to very severe obstruction. ${ }^{15}$ Moreover, the subjects were clinically stable and had no history of infection and no exacerbation of respiratory symptoms or changes in medication for at least two months before the study. Additionally, the subjects did not present with cardiac, rheumatic, or an associated orthopedic disease that would impede them from performing the proposed evaluation tasks, and all were ex- or nonsmokers.

Patients were excluded from the study when the type of medication was modified during the study, in cases of uncontrolled arterial hypertension or hypoxemia (peripheral oxygen saturation $\left[\mathrm{SpO}_{2}\right]$ ) below $85 \%$ at rest), or for refusal to provide written informed consent.

\section{Measurements}

All patients answered a questionnaire related to their physical activity routine, namely, the Modified Baecke Questionnaire, which includes an evaluation of habitual physical activity in the elderly (MBQ), ${ }^{16,17}$ given that the majority of patients were elderly $(80 \%) .{ }^{18}$

The patients with COPD were sent to the Respiratory Physiotherapy Service at the institution, where they underwent general physical and specific respiratory exams and were informed of the proposed protocols.

The complete evaluation was carried out on four separate days: an initial evaluation, administration of the questionnaires, and anthropometric evaluation took place on the first day; the 6MWT and the 6MWTT, with a rest interval of $30 \mathrm{~min}$ between them, were administered on the second day; the HGT was given on the third day; and the ADL Test, including the STST, was administered on the fourth day. 


\section{BODE Index}

The BODE Index Score, which varies from zero to ten, was calculated for each individual by summing the points for each variable: $\mathrm{BMI}_{\mathrm{H}} \mathrm{FEV}_{1}$, dyspnea according to the Medical Research Council Dyspnea Scale (MRC), and distance walked (DW) in the 6MWT. Score classification was divided into quartiles: quartile 1 (Q1), from 0 to 2 points; quartile 2 (Q2), from 3 to 4 points; quartile 3 (Q3), from 5 to 6 points; and quartile 4 (Q4), from 7 to 10 points. A higher BODE index score indicates a greater probability of patient mortality. ${ }^{8}$

\section{Activities of Daily Living Assessment}

The activities that involved effort of the UL and LL included brushing teeth, combing hair, taking a shower and drying off, putting on shoes, lifting and lowering containers to a shelf at eye level, lifting and lowering containers to a shelf above the height of the scapula, hanging clothes on a clothesline, and sweeping. These activities were simulated in the same manner as performed at home. The order of the activities was determined randomly during the evaluation, and each individual was asked only to complete the task. The task times were not pre-determined, with the exception of the six-minute duration for sweeping. The container lifting activities were adapted from the methodology of Velloso et al. ${ }^{4}$

The interval between each task lasted from three to five minutes or until the variables studied returned to baseline. Variables monitored for each ADL were $\mathrm{SpO}_{2}$ using a pulse oximeter (Oxypleth ${ }^{\circledR}$ DX2405), heart rate (HR) using a frequency meter $\left(\right.$ Polar $\left.^{\circledR}\right)$, and sensation of dyspnea using the Modified Borg Scale - CR10. Blood pressure (BP) was also verified by sphygmomanometer $\left(\mathrm{BD}^{\circledR}\right)$ and stethoscope $\left(\right.$ Littmann $\left.^{\circledR}\right)$. All variables were recorded at rest at the end of each activity and during the interval between activities.

The activities were simulated without the collection of gases two days before the beginning of the test in order to eliminate any learning curve effect.

\section{Six Minute Walking Test in a Hallway and on a Tread- mill}

The 6MWT was conducted in a flat corridor measuring $30 \mathrm{~m}$ in length. The patients walked unaccompanied during the test, ${ }^{14,19,20}$ but were given verbal encouragement at standardized one minute intervals. ${ }^{19}$

The 6MWTT was conducted on a treadmill (Inbramed ${ }^{\circledR}$ ) at a pre-established velocity in $\mathrm{Km} / \mathrm{h}$ in accordance with the tolerance of each subject ${ }^{9}$ and with the same standards used for the 6MWT. Two tests were performed on alternate days to eliminate the effect of any learning curve. $\mathrm{SpO}_{2}, \mathrm{HR}$, sensation of dyspnea, and BP at rest were monitored during both tests.

\section{Sit-To-Stand Test}

The Sit-to-Stand Test has been recommended as an alternative to indirectly measure LL strength and is considered as a predictor of severity by Ozalevli et al. ${ }^{10}$ In this study, a chair with a seat height of $46 \mathrm{~cm}$ and no arm supports was utilized. The patients were instructed to keep their UL at their waist and sit down and get up from the chair while holding their backs straight and feet supported by the floor for a period of two minutes, in accordance with the methodology described by Ozalevli et al. ${ }^{10}$

The patients were provided with pre-established verbal encouragement each minute. In addition, measurements were obtained for $\mathrm{SpO}_{2}, \mathrm{HR}$, sensation of dyspnea, and BP both at rest and during the test.

\section{Evaluation of UL Muscle Strength}

Measurement of the isometric muscular force of the UL was obtained from the amount of hand grip strength measured by a Jamar $^{\circledR}$ manual dynamometer in force per kilogram (kgf), which is recommended by the American Society of Hand Therapists (ASHT). ${ }^{21}$ In the protocol utilized, measurements were first obtained for the dominant upper limb, followed by measurements of the non-dominant limb. ${ }^{22}$ The measurements were taken in sitting and standing postures at the following four angles: seated with the arms parallel to the trunk, with the elbow bent at $90^{\circ}$ and the forearm and wrist in a neutral position, and in an orthostatic posture with the upper limb positioned by a goniometer at angles of $0^{\circ}, 90^{\circ}$, and $135^{\circ}$, the same angles used during the ADL evaluation. Five Maximum Voluntary Contractions (MVC) were performed with a rest interval between each of $30 \mathrm{sec}^{20}$ The mean of the repetitions for each limb was used for statistical analysis based on the reference values described by Mathiowetz et al. ${ }^{11,22}$

\section{Analysis of Gases}

Respiratory gas collection was performed during ADL, 6MWTT, and STST using a $\mathrm{VO}_{2000}$ Metabolic System $\left(\right.$ MedGraphics $\left.{ }^{\circledR}\right)$. The system measured micro-samples of the mean of expired gases collected every $20 \mathrm{sec}$. The data produced were digitalized in real time: $\dot{V}_{\mathrm{E}}=$ volume of air expired in liters per min. expressed in BTPS (Body Temperature, Pressure, Saturated), $\dot{V} \mathrm{O}_{2}=$ volume of oxygen 
consumption in liters per min. expressed in STPD (Standard Temperature and Pressure Dry), and $\dot{V} \mathrm{CO}_{2}=$ carbonic gas consumption in liters per min. expressed in STPD. ${ }^{20,23}$ A pneumotachometer with bidirectional flow (low flow) was coupled to a face mask. Before the test, the patients remained seated for placement of the mask and adaptation to the system.

\section{Statistical Analyses}

The Shapiro Wilk Statistical Test was utilized to verify the normality of the data expressed as the mean \pm standard deviation, minimal and maximal values. To evaluate the correlation between variables, the Pearson and Spearman coefficients were utilized for parametric and non-parametric variables respectively. Statistical analyses were performed using SPSS software (release 13.0 for Windows), and the GraphPad StatMate software program was used to calculate the power. $\mathrm{p}<0.05$ was considered as statistically significant.

\section{RESULTS}

Anthropometric values, pulmonary function characteristics, respiratory frequency values at rest, and MBQ and BODE Index (Total score) values - for which three patients scored in Q1 and seven scored in Q2 - are shown in table 1.

The data presented in table 2 show that there was no correlation between the BODE Index (Total Score) and the $\dot{V}_{\mathrm{E}}, \dot{V} \mathrm{O}_{2}$, and $\dot{V} \mathrm{CO}_{2}$ variables in the assessment of ADL or the walking speed in the 6MWTT. A negative correlation was found, however, between the BODE Index and the

Table 1 - Anthropometric and Pulmonary Function Characteristics, Modified Baecke Questionnaire, and BODE Index of the patients evaluated

\begin{tabular}{lcc}
\hline Variables & Mean \pm SD & Min-Max Values \\
\hline Age (years) & $71.00 \pm 7.63$ & $58.00-80.00$ \\
Weight (kg) & $70.67 \pm 9.36$ & $48.00-84.00$ \\
Height (m) & $165.80 \pm 5.05$ & $155.50-172.00$ \\
BMI (kg/m $)^{2}$ & $25.68 \pm 2.76$ & $19.98-28.58$ \\
FEV $_{\mathbf{1}}(\%$ predicted) & $45.83 \pm 14.25$ & $24.20-67.00$ \\
FVC (\% predicted) & $77.45 \pm 16.11$ & $59.64-103.20$ \\
FEV $/$ FVC (\% predicted) & $44.70 \pm 11.84$ & $28.40-65.90$ \\
MVV (\% predicted) $_{\text {RF at rest (rpm) }}$ & $50.43 \pm 17.84$ & $18.00-71.00$ \\
MBQ & $18.00 \pm 2.34$ & $13.00-22.00$ \\
BODE Index (total score) & $8.06 \pm 4.66$ & $2.11-15.45$ \\
\hline
\end{tabular}

$\mathrm{SD}=$ Standard Deviation; $\mathrm{BMI}=$ Body mass Index $\mathrm{FEV}_{1}=$ Forced Expiratory Volume in the First Second; FVC= Forced Vital Capacity; FEV,/FVC= $\mathrm{FEV}_{1} / \mathrm{FVC}$ ratio; $\mathrm{MVV}=$ Maximum Voluntary Ventilation; $\mathrm{RF}=$ Respiratory Frequency; $\mathrm{MBQ}=$ Modified Baecke Questionnaire; BODE Index = Body Mass Index, Airflow Obstruction, Dyspnea and Exercise Capacity Index.
Table 2 - Correlation between the BODE Index and the Variables Studied

\begin{tabular}{lll}
\hline & $\mathbf{r}$ & $\mathbf{p}$ \\
\hline Dependent Variable & & $\begin{array}{l}\text { Independent } \\
\text { Variable }\end{array}$ \\
\hline & & BODE Index \\
Variables ADL $\left(\dot{V}_{\mathrm{E}}, \dot{V} \mathbf{O}_{2}, \dot{V} \mathbf{C O}_{2}\right)$ & --- & $>0.05$ \\
Speed 6MWTT & ---- & $>0.05$ \\
DW 6MWTT & -0.86 & $<0.05^{*}$ \\
Number of Repetitions STST & -0.66 & $<0.04^{\dagger}$ \\
HG URL & & \\
Sitting & -0.83 & $<0.00^{\dagger \dagger}$ \\
Standing $90^{\circ}$ & -0.76 & $<0.02^{\dagger}$ \\
Standing $135^{\circ}$ & -0.76 & $<0.02^{\dagger}$ \\
HG ULL & & \\
Sitting & -0.83 & $<0.00^{\dagger \dagger}$ \\
Standing $90^{\circ}$ & -0.76 & $<0.02^{\dagger}$ \\
\hline
\end{tabular}

Pearson: $* \mathrm{p}<0.05$. Spearman: ${ }^{\dagger} \mathrm{p}<0.05 ;{ }^{\dagger} \mathrm{p}<0.01$. BODE Index $=$ Body Mass Index, Airflow Obstruction, Dyspnea and Exercise Capacity Index; $\mathrm{ADL}=$ Activities of Daily Living; $\dot{V}_{\mathrm{E}}=$ Pulmonary Ventilation; $\dot{V} \mathrm{O}_{2}=$ Oxygen Consumption; $\dot{V} \mathrm{CO}_{2}=$ Carbon Dioxide Production; $6 \mathrm{MWTT}=$ Six-Minute Treadmill Walking Test; TSTS $=$ Sit-To-Stand-Test HG $=$ Hand Grip; URL= Upper Right Limb; ULL= Upper Left Limb.

DW in 6MWTT $(r=-0.86)$, the number of repetitions in STST $(r=-0.66)$, the muscle strength for Upper Right Limb (URL) and Upper Left Limb (ULL) in the seated $(r=-0.83)$ and standing $90^{\circ}(\mathrm{r}=-0.76)$ positions, and the URL in the standing position at $135^{\circ}(\mathrm{r}=-0.76)$.

\section{DISCUSSION}

COPD is a systemic disease in which different factors determine its prognosis such as physical exercise intolerance ${ }^{24-28}$ associated with limitations of the ventilatory system and gas exchange and dysfunction of the peripheral skeletal musculature of the UL and LL. ${ }^{1,2}$

In accordance with the reference values described by Mathiowetz et al., ${ }^{22}$ our patients presented relatively weak UL musculature, differing from the results found by Dourado, ${ }^{29}$ but this assessment did not impede the individuals from performing the ADL tasks. This observation was likely due to the predominant use of the UL in the performance of ADL and the large number of scapular muscles responsible for the elevation of the UL, which concomitantly participate in respiratory movements during forced respiration. The performance of ADL is important for the maintenance of the muscular strength of these $\operatorname{limbs}^{30,31}$ by reducing impairment of the peripheral musculature as a consequence of disuse.

With regard to peripheral muscle impairment, some authors state that there is a relationship between low BMI and such impairment, with a consequent reduction of 
exercise capacity in patients with COPD. ${ }^{32-34}$ This suggests that when an individual presents with a low BMI, it can be due not only to a reduction in muscle mass, but also to nutritional depletion, which results in low energy reserves that limit the execution of activities. ${ }^{35}$ In the present study, however, the patients presented peripheral muscle weakness in the UL, but the majority also had a normal BMI. These results support the idea that BMI may not adequately identify the loss of muscle mass in patients with COPD. ${ }^{36,37}$ Other factors that may be associated with a weak UL musculature include prolonged use of corticosteroids, which, according to Dourado, cause protein degradation. ${ }^{38}$

Muscular limitations that functionally incapacitate the performance of the proposed ADL and the LL tests were not verified.

In the current study, the BODE Index for patients with COPD presented a maximum of 4 points in the total score due to impaired pulmonary function and a lower tolerance for physical exercise. This was verified by the values obtained for $\mathrm{FEV}_{1}$ and $\mathrm{DW}$ in the 6MWT and is in agreement with Pitta et al. ${ }^{39}$ and Celli et al., ${ }^{8}$ who cite the BODE Index as a predictor of disease severity that indirectly evaluates exercise capacity and mortality risk. The score of 4 observed in our COPD population classified them as low mortality risk, in support of our other results presented herein.

With regard to the correlations found, the BODE Index was negatively correlated with DW in the 6MWTT, the number of repetitions in STST, and the HGT. These results suggest that a lower BODE Index score indicates greater hand grip strength, greater DW in 6MWTT, and a greater number of repetitions in STST. Having demonstrated a correlation of the predictor of severity with functional performance in both the LL and UL tests as carried out for the performance of ADL by patients with COPD suggests that these tests are also good predictors of the functional assessment when related to the BODE Index, corroborating Ozalevli et al. ${ }^{10}$
Results for DW in 6MWT and 6MWTT revealed a strong positive correlation between the tests and both tests displayed a strong positive correlation with HGT, corroborating previous studies. ${ }^{14,40,41}$ Moreover, while HGT is a direct measurement of peripheral muscle strength in the hand and UL, it was also found to be a predictor of DW in 6MWTC in patients with COPD and in healthy elderly individuals, strengthening the hypothesis that hand grip strength is a good predictor of mortality that may later be integrated into the BODE Index.

The results found in this study support the influence of HGT in DW, as previously verified by Dourado et al. ${ }^{40}$ Although we found no correlation with the number of repetitions in STST, corroborating findings by Ozalevli et al., ${ }^{10}$ the HGT has been considered as a good predictor of the functional status of patients with COPD.

It is important to note that the difficulties and limitations encountered in our study were related to the choice of activities evaluated, the execution time of each activity, the predominance of patients with moderate obstruction, and the metabolic system utilized, without a telemetry system, all reflecting the need to review whether the methods employed were the best form of evaluation and suggesting further studies on this topic.

\section{CONCLUSION}

In conclusion, this study does not support the hypothesis that there is a correlation between the BODE Index and ventilatory and metabolic responses during the performance of ADL. However, these data do support the hypothesis that there is a correlation between the BODE Index and the variables assessed in the 6MWTT, STST, and HGT in moderate to very severe COPD patients, suggesting their use in a predictive index of physical exercise capacity, perhaps used as a complement to the BODE Index. However, we did not assess whether these results hold true for patients with a mild obstruction.

\section{REFERENCES}

1. Palange P, Forte S, Onorati P, Paravati V, Manfredi F, Serra P, et al. Effect of reduced body weight on muscle aerobic capacity in patients with COPD. Chest. 1998;114:12-8.

2. Hamilton AL, Killian KJ, Summers E, Jones NL. Muscle strength, symptom intensity and exercise capacity in patients with cardiorespiratory disorders. Am J Respir Crit Care Med. 1995;152:2021-31.

3. Man WD, Soliman MGG, Nikoletou D, Harris ML, Rafferty GF, Mustfa $\mathrm{N}$, et al. Non-volitional assessment of skeletal muscle strength in patients with chronic obstructive pulmonary disease. Thorax. 2003;58:665-9.

4. Velloso M, Stella SG, Cendon S, Silva AC, Jardim JR. Metabolic and ventilatory parameters of four activities of daily living accomplished with arms in COPD. Chest. 2003;123:1047-53.

5. Wouters EFM. Nutrition and metabolism in COPD. Chest. 2000; 117(5 suppl.1):274-80S

6. Orozco-Levi M. Structure and function of the respiratory muscles in patients with COPD: impairment or Adaptation? Eur Respir J. 2003;22 (suppl. 46):41-51S.

7. Engelen MP, Wouters EF, Deutz NE. Factors contributing to alterations in skeletal muscle and plasma amino acid profile in patients with chronic obstructive pulmonary disease. Am J Clin Nutr. 2000;72:1480-7. 
8. Celli BR, Cote CG, Marin JM. Casanova C, Oca MM, Mendez RA, e al. The body-mass index, airflow obstruction, dyspnea, and exercise capacity index in chronic obstructive pulmonary disease. N Engl J Med. 2004;350:1005-12.

9. Stevens D, Elpern E, Sharma K, Szidon P, Ankin M, Kesten S. Comparison of hallway and a treadmill six-minute walk tests. Am J Respir Crit Care Med. 1999;160:1540-3.

10. Ozalevli S, Ozden A, Itil O, Akkocli A. Comparison of sit-to-stand test with 6 min walk test in patients with chronic obstructive pulmonary disease. Respir Med. 2007;101:286-93.

11. Figueiredo IM, Sampaio RF, Mancini MC, Silva FCM, Souza MAP. Teste de força de preensão utilizando dinamômetro Jamar. Acta Fisiatr. 2007;14:104-10.

12. Velloso M, Jardim JR. Funcionalidade do paciente com doença pulmonar obstrutiva crônica e técnicas de conservação de energia. J Bras Pneumol. 2006;32:580-6.

13. Celli BR. The clinical use of upper extremity exercise. Clin Chest Med. $1994 ; 15 ; 2 ; 339-49$.

14. Enright PL, Mcburnie MA, Bittner V, Tracy RP, McNamara R, Arnold A and Newman AB. The 6-min walk test. A quick measure of functional status in elderly adults. Chest. 2003;123:387-98.

15. Global strategy for the Diagnosis, Management and Prevention of Chronic Obstructive Lung Disease. GOLD Executive Summary. Rabe KF et al. Am J Respir Crit Care Med. 2007;176:532-55.

16. Voorrips LE, Ravelli AC, Dongelmans, PC, Deurenberg P, Vanstaveren WA. A physical activity questionnaire for the elderly. Med Sci Sports Exerc. 1991;23:974-9.

17. Mazo GZ, Benedetti TB, Mota J, Barros MVG. Validade Concorrente e Reprodutibilidade Teste-reteste do Questionário de Baecke Modificado Para Idosos. Rev Bras Atividade Física e Saúde. 2001;6:5-11.

18. Estatuto do Idoso. Série E. Legislação de Saúde. $1^{\mathrm{a}}$ ed. $2^{\mathrm{a}}$ reimpressão. Brasília - DF, 2003

19. American Thoracic Society. ATS statement: guidelines for thesix-minute walk test. Am J Respir Crit Care Med. 2002;166:111-7.

20. Neder JA, Nery LE. Fisiologia Clínica do Exercício. $1^{\mathrm{a}}$ ed. São Paulo, Brazil: Artes Médicas, 2003.

21. Fess EE. Grip strenght. In: Casanova JS,editor.Clinical Assesment Recommendations. $2^{\text {nd }}$ ed. Chicago: American Society of Hand Therapists; 1992.

22. Mathiowetz V, Kashman N, Volland G, Weber K, Dowe M, Rogers S Grip and pinch strength: normative data for adults. Arch Phys Med Rehabil. 1985;66:69-74.

23. Crouter SE, Antczak A, Hudak JR, DellaValle DM, Haas JD. Accuracy and reliability of the ParvoMedics TrueOne 2400 and MedGraphics VO2000 metabolic systems. Eur J Appl Physiol. 2006;98:139-51.

24. Maltais F, Jobin J, Sullivan M J, Bernard S, Whittom F, Killian KJ, Desmeules M, Belanger M, LeBlanc P. Metabolic and hemodynamic responses of lower limb during exercise in patients with COPD. J Appl Physiol. 1998;84:1573-80.

25. Alves Júnior L, Rodrigues AJ, Evora PR, Basseto S, Scorzoni Filho A, Luciano PM, et al. Risk factors in septuagenarians or elderly patients undergone coronary artery bypass grafting and or valves operations. Rev Bras Cir Cardiovasc. 2008;23:550-5.
26. Costa D, Barbalho MC, Miguel GP, Forti EM, Azevedo JL. The impact of obesity on pulmonary function in adult women. Clinics. 2008;63:71924

27. Barbosa TM, Sgarbieri RN, Moreira Neto FF, Vieira FF, Pereira Gde A, de Rezende Filho AV, et al. Evaluation of the NNECDSG Score in a Brazilian public hospital. Rev Bras Cir Cardiovasc. 2007;22:212-7.

28. Toledo A, Borghi-Silva A, Sampaio LM, Ribeiro KP, Baldissera V, Costa D. The impact of noninvasive ventilation during the physical training in patients with moderate-to-severe chronic obstructive pulmonary disease (COPD). Clinics. 2007;62:113-20

29. Dourado VZ. Avaliação de fatores determinantes da tolerância ao exercício em pacientes com doença pulmonar obstrutiva crônica. [Dissertação de Mestrado]. Botucatu: Faculdade de Medicina de Botucatu. Universidade Estadual Paulista "Júlio de Mesquita Filho", UNESP; 2006

30. Bernard S, Whittom F, Leblanc P, Jobin J, Belleau R, Bérubé C, et al. Aerobic and strength training in patients with chronic obstructive pulmonary disease. Am J Respir Crit Care Med. 1999;159:896-901.

31. Gosselink R, Troosters T, Decramer M. Distribution os muscle weakness in patients with stable chronic obstructive pulmonary disease. J Cardiopulm Rehabil. 2000;4:353-60.

32. Yoshikawa M, Yoneda T, Takenaka H, Fukuoka A, Okamoto Y, Narita $\mathrm{N}$, et al. Distribution of muscle mass and maximal exercise performance in patients with COPD. Chest. 2001;11:93-8.

33. Debigaré R, Maquis K, Côté C, Tremblay RR, Michaud A, Leblanc P, Maltais F. Catabolic/anabolic balance and muscle wasting inpatients with COPD. Chest. 2003;124:83-9.

34. Saey D, Debigaré R, Leblanc P, Mador MJ, Côtë CH, Jobin J, Maltais F. Contractile leg fatigue after cycle exercise: A fator limiting exercise in patients with chronic obstructive pulmonary disease. Am J Respir Crit Care Med. 2003;168:425-30.

35. Landbo C, Prescott E, Lange P, Vestbo J, Almdal P. Prognostic value of nutritional status in chronic obstructive pulmonary disease. Am J Respir Crit Care Med. 1999;160:1856-61.

36. Eid AA, Ionescu, AA, Nixon L, Lewis-Jenkins V, Matthews SB, Griffiths TL, Shale DJ. Inflamatory response and body composition in chronic obstructive pulmonary disease. Am J Respir Crit Care Med. 2001;164:1414-8

37. Mador MJ. Muscle mass, not body weight, predicts outcome in patients with chronic obstructive pulmonary disease. Am J Respir Crit Care Med. 2002;166:787-8.

38. Dourado VZ, Tanni SE, Vale AS, Faganello MM, Sanchez FF, Godoy I. Manifestações sistêmicas na doença pulmonar obstrutiva crônica. J Bras Pneumol. 2006;32:161-71.

39. Pitta F, Troosters T, Probst V, Lucas S, Decramer M, Gosselink R. Potential consequences for stable chronic obstructive pulmonary disease patients who do not get the recommended minimum daily amount of physical activity. J Bras Pneumol. 2006;32:301-8.

40. Dourado VZ, Antunes LCO, Tanni SE, Paiva SAR, Padovani CR, Godoy I. Relationship of upper-limb and thoracic muscle strength to 6-min walk distance in COPD patients. Chest. 2006;129:5551-7.

41. Gosselink R, Troosters T, Decramer M. Peripheral muscle weakness contributes to exercise limitation in COPD. Am J Respir Crit Care Med. 1996;153:976-80 